\title{
Spontaneous Epidural Hematoma of the Cervical Spine Mimicking a Cerebrovascular Accident: A Case Report
}

\section{Hematoma epidural espontâneo da coluna cervical imitando acidente vascular cerebral: Relato de caso}

\author{
Mohammad Jamali ${ }^{2}$ Sepehr Entezam ${ }^{3} \quad$ Sulmaz Ghahramani ${ }^{1}$ \\ ${ }^{1}$ Health Policy Research Center, Institute of Health, Shiraz University \\ of Medical Sciences, Shiraz, Iran \\ 2 Department of Neurosurgery, Shiraz University of Medical Sciences, \\ Shiraz, Iran \\ ${ }^{3}$ Student Research Committee, Fasa University of Medical Sciences, \\ Fasa, Iran \\ Arq Bras Neurocir 2018;37:213-216 \\ Address for correspondence Sulmaz Ghahramani, Health Policy \\ Research Center, Institute of Health, Shiraz University of Medical \\ Sciences, Shiraz, Iran, 71348-45794 (e-mail: suli.ghahraman@gmail.com).
}

\begin{abstract}
Keywords

- spontaneous spinal epidural hematoma

- cervical spine
\end{abstract}

\section{Resumo}

\section{Palavras-chave}

- hematoma epidural espinhal espontâneo

- coluna cervical
Objective The present study is a case report of a 57-year-old female with controlled hypertension who presented with spontaneous spinal epidural hematoma (SSEH) mimicking a cerebrovascular accident (CVA) and was successfully treated by surgical decompression.

Methods A 57-year-old woman with a medical history of hypertension presented with a sudden onset of weakness in the right upper and lower extremities. Weakness of grade 3/5 was noted in her right upper and lower extremities, but there was no motor weakness of the right facial muscles. A magnetic resonance imaging (MRI) exam of the cervical spine revealed an epidural hematoma extending from level C5 to level C7, causing spinal cord compression.

Results During surgery, a cervical spinal epidural hematoma (SEH) was evacuated. Postoperatively, the power in both limbs improved to grade $5 / 5$ just after surgery.

Conclusions A high degree of suspicion, meticulous history taking, and physical examination have a great importance in these rare conditions because anticoagulant therapy as a routine treatment for ischemic CVA could be life-threatening.

Objetivo $\mathrm{O}$ presente estudo se trata de um relato de caso de uma paciente de 57 anos, com hipertensão controlada, que apresentou um hematoma epidural espinhal espontâneo (HEEE) imitando um acidente vascular cerebral (AVC), e que foi tratada com sucesso através de descompressão cirúrgica.

Métodos Uma mulher de 57 anos com um histórico de hipertensão apresentou um súbito princípio de fraqueza nas extremidades superior e inferior do lado direito. Foi notada força muscular de grau 3/5 em suas extremidades superior e inferior do lado direito, mas não houve fraqueza motora dos músculos faciais no lado direito. Um exame de ressonância magnética (RM) da coluna cervical revelou um hematoma epidural estendendo-se do nível $\mathrm{C} 5$ ao nível $\mathrm{C7}$, causando uma compressão medular. received

May 22, 2018

accepted

June 8,2018

published online

August 22, 2018
DOI https://doi.org/

10.1055/s-0038-1668551. ISSN 0103-5355.
Copyright $(2018$ by Thieme Revinter

Publicações Ltda, Rio de Janeiro, Brazil
License terms

(ㄷ) (i) $\ominus$ (5) 
Resultados Durante a cirurgia, um hematoma epidural espinhal (HEE) cervical foi removido. No pós-operatório, a força muscular em ambos os membros aumentou para grau 5/5 logo após a cirurgia.

Conclusões Um alto grau de suspeita, um meticuloso acompanhamento do histórico, e a avaliação física possuem grande importância nesses quadros clínicos raros, pois a terapia anticoagulante como procedimento habitual de tratamento para o AVC isquêmico pode apresentar riscos à vida.

\section{Introduction}

Spontaneous spinal epidural hematoma (SSEH) is a very rare condition that requires an urgent diagnosis. The incidence of SSEH is estimated to be 1 patient per $1,000,000$ individuals. Typically, SSEH presents an acute onset of severe back and neck pain, and signs of compression of the spinal cord develop rapidly. Although hemi- paresis due to SSEH is a relatively uncommon symptom compared with quadriparesis, to the best of our knowledge, a few cases of hemiparesis due to SSEH have been reported until now. Patients with hemiparesis due to SSEH have often been misdiagnosed as presenting with a cerebral infarction and treated with antiplatelet or anticoagulation therapy. This is one of the pitfalls in emergency
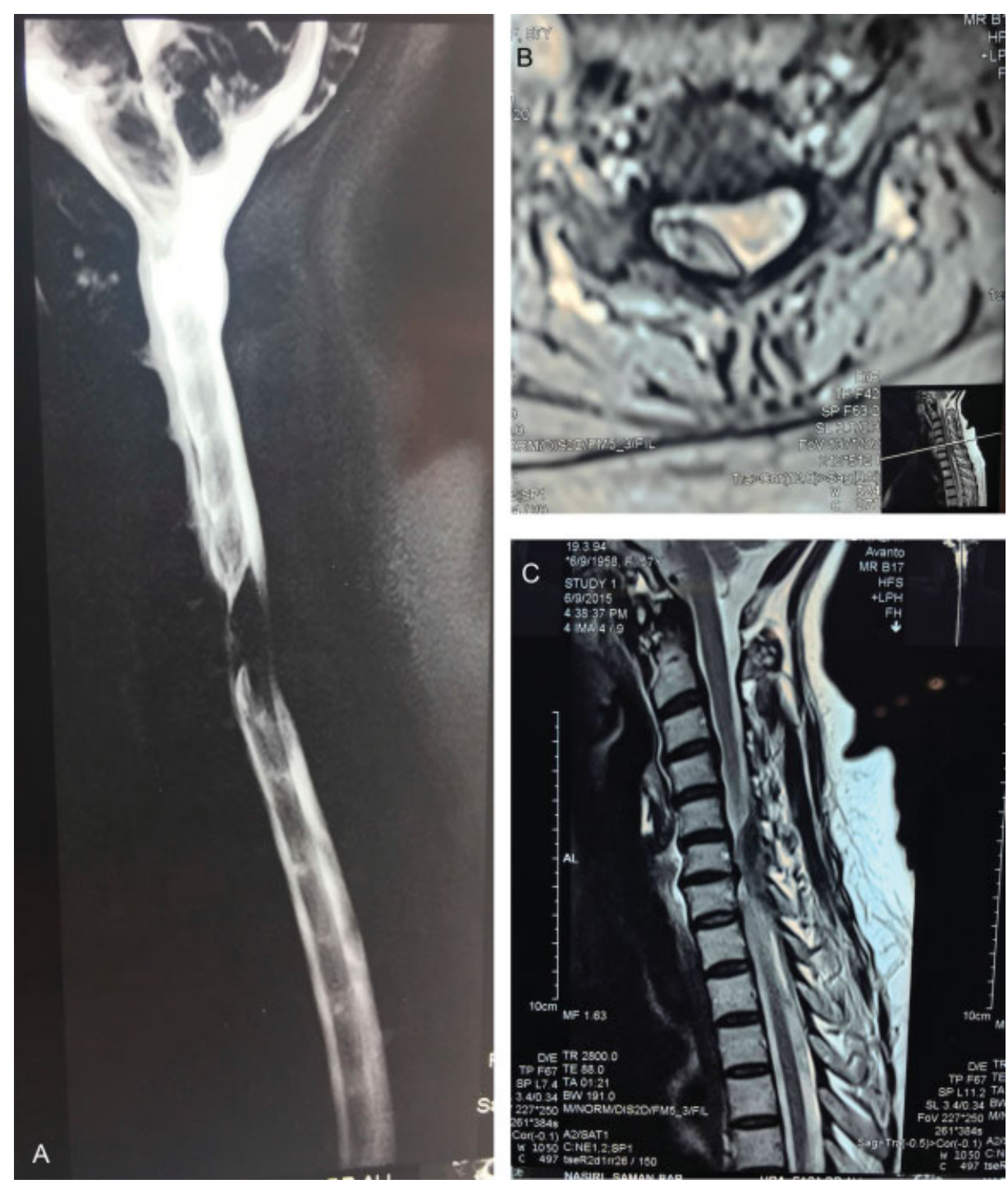

Fig. 1 MRI and MR myelogram from C5 to C7 epidural hematoma. (A) MR myelogram cut off. (B) Axial T2 image which shows right side epidural hematoma. (C) Sagittal image of C5 to C7 epidural hematoma. 
stroke cases. In the present study, we present a case report of a 57-year-old female with controlled hypertension who presented with SSEH mimicking a cerebrovascular accident (CVA) and was successfully treated with surgical decompression.

\section{Case Report}

A 57-year-old woman with a medical history of hypertension presented to our emergency department complaining of a sudden onset of weakness in the right upper and lower extremities. There was no history of trauma, infection, or drug administration. Upon neurological examination, weakness of grade 3/5 was noted in her right upper and lower extremities, while there was no motor weakness of the right facial muscles. Her sensory function was completely preserved. All of the blood count, blood urea nitrogen (BUN), creatinine, international normalized ratio (INR), prothrombin time (PT), partial thromboplastin time (PTT), electrolytes and troponin titer were within the normal limits. Aspirin was administered by a neurologist with a strong suspicion of a transient ischemic attack (TIA). Imaging studies of the brain showed no hemorrhagic lesion, no tumor or arteriovenous malformation. A magnetic resonance imaging (MRI) exam of the cervical spine revealed an epidural hematoma extending from level C5 to level C7, causing spinal cord compression. (-Fig. 1) Aspirin was discontinued and the patient was submitted to a surgical treatment for decompression laminectomy. A bilateral C5 to C7 laminectomy was performed. The patient was informed that her condition would be published anonymously and signed a written informed consent. During the operation, an epidural hematoma was evacuated. (-Fig. 2) Postoperatively, the power in both limbs improved to grade 5/5 just after the surgery.

\section{Discussion}

Spontaneous spinal epidural hematoma is rare, and the annual incidence is 1 case per $1,000,000$ individuals. ${ }^{1}$ The spontaneous development of SEHs is most frequent after the fourth or fifth decade of life. However, it has been reported to occur in all age groups, and it is a very rare clinical entity in children. The male/ female ratio is $1.4: 1 .^{1}$ Although SSEH is an accumulation of blood in the vertebral epidural space in the absence of trauma or iatrogenic procedures such as lumbar puncture, there is still no consensus regarding its definition. Some authors include hematomas secondary to coagulopathy, vascular malformations, hemorrhagic tumors and also pain control procedures. ${ }^{2,3}$ Other authors claim, however, that hematoma can be labeled as spontaneous only when it is of idiopathic origin. ${ }^{2}$ Patients often present with a sudden onset of back or neck pain around the affected vertebrae, with corresponding dermatomal radiculopathy, which then rapidly progresses to symptoms and signs of spinal cord compression. This represents a neurosurgical emergency. Without prompt diagnosis and treatment, there will be permanent neurological deficits or even death. ${ }^{4,5}$ The most common cause of hemiparesis is a cerebrovascular incident, such as cerebral infarction. Although hemiparesis due to

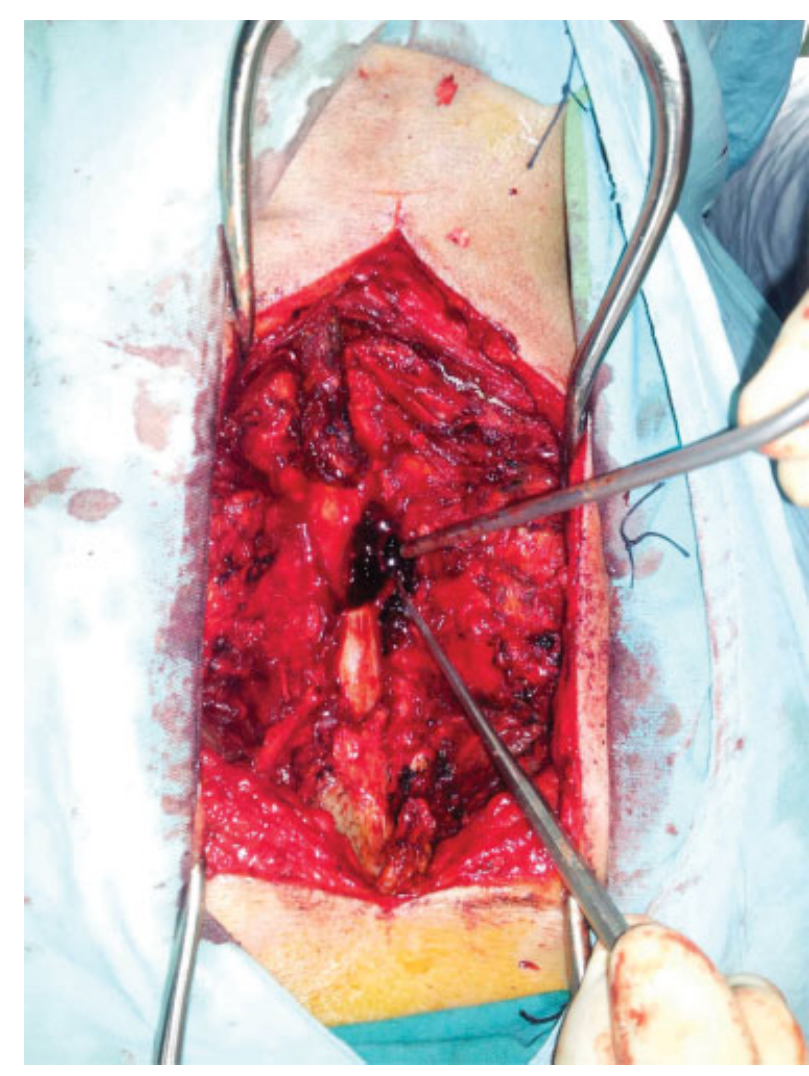

Fig. 2 Intra-operative image of right side clotted blood in epidural space.

spinal cord disorders is rare, injury of the unilateral corticospinal tract in the cervical spinal cord causes hemiparesis. Therefore, cervical SSEH, in which quadriparesis is a common symptom, can cause hemiparesis. ${ }^{6}$

Patients with hemiparesis due to SSEH have often been misdiagnosed as having cerebral infarction and treated with antiplatelet or anticoagulation therapy. As a result, the hemiparesis worsened, and only then were they diagnosed with SSEH. How can one distinguish the symptoms of SSEH with hemiparesis from cerebral infarction? Typically, SSEH is characterized by the sudden onset of neck and back pain followed by motor and sensory dysfunction. ${ }^{6}$ As you see in the case reported in the present study, the patient did not present with acute neck pain, and the only symptom was progressive hemiparesis, which made a neurologist colleague suspect of TIA and administer anticoagulant therapy.

The preferred diagnostic tool for SSEH is an MRI exam, which can reveal the location and extent of the hematoma, the degree of spinal cord compression and the signal in the spinal cord, although a computed tomography (CT) scan may be useful for cases in which MRI is contraindicated. The MRI appearance of the hematoma depends on the hematoma stage. ${ }^{5,7}$ It typically shows biconvex hematomas in the epidural space with well-defined borders tapering superiorly and inferiorly. ${ }^{1}$ In the present case, the MRI revealed a heterogeneous hyperintense extradural lesion in the T1 sequence and a heterogeneous hypointense lesion in the T2 sequence from the fifth to the seventh cervical vertebrae. No vascular or tumor lesion were detected during operation. 
The differential diagnosis of SSEH includes acute herniated intervertebral disc, acute ischemia of the spinal cord, epidural tumor or abscess, spondylitis, transverse myelitis, or even a dissecting aortic aneurysm and acute myocardial infarction. ${ }^{1}$

Spontaneous spinal epidural hematoma is an urgent surgical condition, and the most effective treatment is decompressive laminectomy and prompt drainage of the hematoma. ${ }^{7}$ The postoperative recovery from SSEH depends, predominantly, on the interval between the onset of the symptom and the surgical decompression. ${ }^{2}$ However, conservative treatment has also been documented, and it was employed only when the neurological deficits improved in the early phase or with the coexistence of coagulopathy. Multilevel acute epidural hematomas may be difficult to treat operatively in patients with coagulopathy. Although the functional recovery of these patients may not be complete, the SSEH can be treated without surgery, and the patient should be protected from the significant risk of surgical intervention. ${ }^{1}$ We performed an urgent decompression surgery by bilateral laminectomy and medial facetectomy followed by the evacuation of about $5 \mathrm{ml}$ of clotted extradural hematoma.

\section{Conclusion}

Hemiparesis or hemiplegia without signs and symptoms of cerebral involvement, such as facial hemiparesis or speech disturbance, could be a sign of cervical cord pathology, and in the subset of hemorrhagic lesions, an accurate diagnosis has great importance because anticoagulant therapy as a routine treatment for ischemic CVA could be life-threatening. A high degree of suspicion, meticulous history taking, and physical examination are of great importance in these rare conditions.

Funding

None.

\section{Conflicts of Interest}

The authors have no conflicts of interest to declare.

\section{Acknowledgments}

The authors would like to thank the patient for her cooperation and the staff of the hospital.

\section{References}

1 Baek BS, Hur JW, Kwon KY, Lee HK. Spontaneous spinal epidural hematoma. J Korean Neurosurg Soc 2008;44(01):40-42

2 Lo C-C, Chen J-Y, Lo Y-K, Lai P-H, Lin Y-T. Spontaneous spinal epidural hematoma: a case report and review of the literatures. Acta Neurol Taiwan 2012;21(01):31-34

$3 \mathrm{Nam} \mathrm{KH}$, Choi CH, Yang MS, Kang DW. Spinal epidural hematoma after pain control procedure. J Korean Neurosurg Soc 2010;48 (03):281-284

4 Hussenbocus SM, Wilby MJ, Cain C, Hall D. Spontaneous spinal epidural hematoma: a case report and literature review. J Emerg Med 2012;42(02):e31-e34

5 Zhong W, Chen H, You C, Li J, Liu Y, Huang S. Spontaneous spinal epidural hematoma. J Clin Neurosci 2011;18(11):1490-1494

6 Son S, Kang DH, Choi DS, Kim SK, Lim BH, Choi NC. A case of spontaneous spinal epidural hematoma mimicking a stroke. Neurologist 2012;18(01):41-43

7 Buyukgol H, Ilik MK, Ilik F. Ischemic stroke differential diagnose: spontaneous spinal epidural hematoma can be fatal. Am J Emerg Med 2015;33(08):1112.e1-1112.e2 